\title{
Changes in mortality rates and causes of death in a population-based cohort of persons living with and without HIV from 1996 to 2012
}

Oghenowede Eyawo ${ }^{1,2}$ (D), Conrado Franco-Villalobos ${ }^{1}$, Mark W. Hull ${ }^{1}$, Adriana Nohpal ${ }^{3}$, Hasina Samji ${ }^{4}$, Paul Sereda ${ }^{1}$, Viviane D. Lima', Jeannie Shoveller ${ }^{1,5}$, David Moore ${ }^{1}$, Julio S. G. Montaner ${ }^{1,6}$, Robert S. Hogg ${ }^{1,2^{*}}$ and for the Comparative Outcomes And Service Utilization Trends (COAST) study

\begin{abstract}
Background: Non-HIV/AIDS-related diseases are gaining prominence as important causes of morbidity and mortality among people living with HIV. The purpose of this study was to characterize and compare changes over time in mortality rates and causes of death among a population-based cohort of persons living with and without HIV in British Columbia (BC), Canada.

Methods: We analysed data from the Comparative Outcomes And Service Utilization Trends (COAST) study; a retrospective population-based study created via linkage between the BC Centre for Excellence in HIV/AIDS and Population Data BC, and containing data for HIV-infected individuals and the general population of BC, respectively. Our analysis included all known HIV-infected adults ( $\geq 20$ years) in BC and a random $10 \%$ sample of uninfected BC adults followed from 1996 to 2012. Deaths were identified through Population Data BC - which contains information on all registered deaths in BC (BC Vital Statistics Agency dataset) and classified into cause of death categories using International Classification of Diseases (ICD) 9/10 codes. Age-standardized mortality rates (ASMR) and mortality rate ratios were calculated. Trend test were performed.
\end{abstract}

Results: 3401 (25\%), and 47,647 (9\%) individuals died during the 5,620,150 person-years of follow-up among 13,729 HIV-infected and 510,313 uninfected individuals, respectively. All-cause and cause-specific mortality rates were consistently higher among HIV-infected compared to HIV-negative individuals, except for neurological disorders. Allcause ASMR decreased from 126.75 (95\% Cl: 84.92-168.57) per 1000 population in 1996 to 21.29 (95\% Cl: 17.79-24. 79) in 2011-2012 (83\% decline; $p<0.001$ for trend), compared to a change from 7.97 (95\% Cl: $7.61-8.33$ ) to 6.87 (95\% Cl: 6.70-7.04) among uninfected individuals (14\% decline; $p<0.001$ ). Mortality rates from HIV/AIDS-related causes decreased by 94\% from 103.85 per 1000 population in 1996 to 6.72 by the 2011-2012 era $(p<0.001)$. Significant ASMR reductions were also observed for hepatic/liver disease and drug abuse/overdose deaths. ASMRs for neurological disorders increased significantly over time. Non-AIDS-defining cancers are currently the leading non-HIV/AIDS-related cause of death in both HIV-infected and uninfected individuals.

(Continued on next page)

\footnotetext{
* Correspondence: rhogg@sfu.ca

'British Columbia Centre for Excellence in HIV/AIDS, St. Paul's Hospital, 608-1081 Burrard Street, Vancouver, BC, Canada

${ }^{2}$ Faculty of Health Sciences, Simon Fraser University, Burnaby, BC, Canada

Full list of author information is available at the end of the article
} 
(Continued from previous page)

Conclusions: Despite the significant mortality rate reductions observed among HIV-infected individuals from 1996 to 2012, they still have excess mortality risk compared to uninfected individuals. Additional efforts are needed to promote effective risk factor management and appropriate screening measures among people living with HIV.

Keywords: Mortality, HIV infection, Age-standardized mortality rate, Mortality rate ratio, Cause of death

\section{Background}

The widespread uptake of combination antiretroviral therapy (cART) has led to substantial reductions in morbidity and mortality associated with HIV/AIDS [1-3]. Over the last 20 years, cART regimens have become, not only more effective and less toxic, but also simpler in terms of pill burden and frequency, thus enhancing adherence $[4,5]$. This has translated into improvement in survival among cART-treated persons living with HIV [6]. Today in many regions, HIV/AIDS is widely viewed as a manageable chronic condition [7], with the life expectancy of HIV-infected individuals receiving cART approaching that of the general population in some settings [8-10].

Improved survival rates now observed among HIVinfected individuals treated with cART have been accompanied by a gradual shift in their morbidity and mortality patterns in some studies $[11,12]$. Non-HIVspecific diseases, including non-AIDS-defining cancers, cardiovascular diseases (CVD), renal and liver diseases, are becoming more prevalent with many HIV-infected individuals now experiencing one or more of these comorbid conditions [11-16]. As a result, causes of death among people living with HIV have shifted in several important ways. In particular, deaths from these chronic diseases and other complications typically associated with natural aging have gained prominence as individuals are living longer on cART. It is thus important to monitor changes in the causes of death as this information will be useful in projecting future morbidity and mortality trends. Ultimately, such knowledge will provide guidance that may inform how risk factors for such increasingly common adverse health outcomes are addressed in this population.

Although decreases in all-cause mortality rates have been well documented among HIV-infected individuals in British Columbia (BC), Canada [1, 6, 17-21], changes in cause-specific deaths in this population following cART introduction in this setting is less well characterized. Furthermore, it is unclear how the trends and causes of death among HIV-infected individuals in this setting compare to that of the general uninfected population. Given the changing pattern of causes of death reported among HIV-infected individuals in other settings after cART introduction [11-14], we hypothesized that similar patterns may be observed among
HIV-infected BC residents. Our objective was, therefore, to characterize the changes in mortality rates and causes of death over time following cART introduction among a population-based cohort of HIV-infected individuals in BC. Secondly, we compared these patterns of death to that observed in a population-based sample of uninfected individuals drawn from the $\mathrm{BC}$ general population over the same time period.

\section{Methods}

\section{Study population and setting}

We used data from the Comparative Outcomes And Service Utilization Trends (COAST) study. COAST is a large population-based retrospective cohort study including longitudinal data of HIV-infected adults $(\geq$ 19 years) and a control group from the general population of $\mathrm{BC}$ residents meeting the age criterion and recruited into the cohort in the period between April 1, 1996 and March 31, 2013. Briefly, the COAST cohort was designed to characterize health outcomes and healthcare utilization of persons living with HIV infection since the introduction of cART and to evaluate differences in these parameters from those observed in the general population. COAST contains de-identified health-related data arising from a unique data linkage between the $\mathrm{BC}$ Centre for Excellence in HIV/AIDS (BCCfE) Drug Treatment Program [22] and Population Data BC [23]. The Drug Treatment Program manages the province-wide antiretroviral therapy dispensation program. It prospectively collects demographic, immunologic, virologic, ART-use and other clinical data on all known HIV-infected individuals who have ever accessed ART, which is accessible at no cost through the BCCfE. Population Data BC is $\mathrm{BC}$ 's repository of individual-level longitudinal data from health administrative databases [24-31]; data that are collected by public bodies for all four million $\mathrm{BC}$ residents.

The follow-up for this analysis started at cohort entry and ended in December 31, 2012. The current analysis is limited to COAST study participants aged 20 years or older with at least one day of follow-up since entering the cohort. This age criterion was necessary to facilitate age groupings by five-year categories and thus permit age standardization of mortality rates. The study population comprised of two distinct cohorts distinguished by 
their HIV status. The HIV-infected cohort is comprised of all age-eligible individuals known to be HIV-positive during the follow-up period. HIV diagnosis was based on the presence of at least one detectable HIV plasma viral load, and/or an initiation of ART as indicated in the BCCfE Drug Treatment Program registry. The HIV case identification was supplemented through administrative health records review of International Classification of Diseases (ICD) -9 and 10 codes for records with at least one documentation of having received care for an HIV/ AIDS-related medical condition or death. The following HIV-related ICD 9/10 codes were used: (i) ICD-9 codes 042-44, V08, 795.71, 795.8; (ii) ICD-10 codes B20-24, R75, Z21; and (iii) ICD-10-CA codes B20-24, R75, Z21. To avoid potential misclassification, we applied a validated HIV case-finding algorithm - an additional criteria of $\geq 1$ inpatient and/or $\geq 3$ outpatient ICD-9/10 codes to potential cases identified within administrative health records [32]. The uninfected cohort was created based on a ten percent randomly generated sample of adult individuals from the general population of $\mathrm{BC}$ over the same time frame and excludes any known HIV-infected individual. The random sample in COAST was created by executing a computer-generated simple random sampling technique to draw a ten percent sample from a combined pool of all distinct individuals with a Personal Health Number (PHN) in the general population of BC and meeting the age eligibility criterion ( $\geq 19$ years) between April 1, 1996 and March 31, 2013. The PHN is a unique identifier that tracks health care system encounters for all $\mathrm{BC}$ residents.

\section{Outcome and definitions}

Our primary outcome was death from any cause. Deaths were identified through the BC Vital Statistics Agency mortality dataset [31], which contains information on all registered deaths in $\mathrm{BC}$ and was accessed through a data linkage conducted by Population Data BC. As part of the death registration in BC as well as elsewhere in Canada, a medical certificate of cause of death is completed by a medical examiner, coroner or other certifier, and elicits relevant information on the nature of the death. We classified deaths based on the underlying cause of death information into categories by causes using ICD-9 codes for deaths through 1999, and ICD-10 codes for deaths from 2000 onwards. The causes of death were grouped into the following categories: HIV/AIDS-related, cancers, CVD, chronic respiratory diseases, drug abuse and overdose, hepatic and liver diseases, neurologic disorders, renal diseases, suicides, unintentional injuries (including accidents), other infectious and parasitic diseases (excluding HIV and viral hepatitis), and 'other causes', which includes all causes of death not listed in the aforementioned categories. Since deaths from cancers such as Kaposi sarcoma, cervical cancer and Non-Hodgkin's lymphoma are typically regarded as AIDS-defining; we grouped codes for such deaths occurring within the HIV-infected cohort under the 'HIV/AIDS-related' cause of death category and excluded them from the 'cancer' category. Table 1 lists the ICD-9/10 codes associated with the causes of death categories.

Table 1 Causes of death categories and the applicable ICD 9 and 10 codes

\begin{tabular}{|c|c|c|}
\hline Cause of death & ICD 9 code & ICD 10 code \\
\hline HIV/AIDS-related & 042-044 & B20-B24 \\
\hline Cancer $^{\mathrm{a}}$ & $140-239$ & C00-D48 \\
\hline Cardiovascular diseases & $410-414,428,430-438,362.3$ & $100-199$ \\
\hline Chronic respiratory diseases & $491,492,496,493$ & J40-J46 \\
\hline Drug abuse and overdose & 304, 305, E850-E858 & F10-F19, F55, X40-X45, T40 \\
\hline Hepatic and liver diseases & $070,570-572,275,456,155,782.4$ & B15-B19, K70-K77 \\
\hline Neurologic disorders & $320-327,330-359$ & F03, G00-G99 \\
\hline Renal diseases & $250.4,403-404,580-590,593,792.5$, V45.1, V42.0 & N00-N07, N17-N19, N25-N27 \\
\hline Suicides & E950-E959 & $\mathrm{X} 60-\mathrm{X} 84, \mathrm{Y} 87.0$ \\
\hline Unintentional injuries (including accidents) $^{b}$ & 800-999, E800-E999 & V01-Y89 \\
\hline Other infectious and parasitic diseases ${ }^{c}$ & $001-139,480-487$ & A00-B99, J10-J18 \\
\hline Other causes & All codes not previously listed & All codes not previously listed \\
\hline
\end{tabular}

Legend: ICD International Classification of Diseases

${ }^{\text {a }}$ Since deaths from cancers such as Kaposi sarcoma, cervical cancer and Non-Hodgkin's lymphoma are typically regarded as AIDS-defining; we grouped codes for such deaths occurring within the HIV-infected cohort under the 'HIV-related' cause of death category and excluded them from the 'cancer' category. The applicable codes are: 176, 180, 200, 202 (ICD 9) and C46, C53, C82 C83 (ICD 10)

${ }^{\mathrm{b}}$ Excludes suicides, drug abuse and overdose codes

'Excludes HIV and viral hepatitis codes 


\section{Statistical analysis}

Crude all-cause and cause-specific mortality rate per 1000 person-years (PY) were calculated from the observed number of deaths and PYs of observation. To account for differences in the age structure and to permit comparability between the HIV-infected and uninfected cohorts, we computed the agestandardized mortality rates (ASMR) using the direct standardization method with the 1991 Canadian censual population as the reference standard population. The 1991 Canadian population is typically used for the standardization of age-specific disease rates in Canada. Additionally, we compared the ASMRs in the cohorts per calendar interval. We divided the observation period into 11 calendar intervals: 1996, 1997-1998, 1999-2000, 2001-2002, 2003-2004, 2005-2006, 2007-2008, 2009-2010, and 2011-2012). Although shorter than the other calendar periods, we elected to include 1996 (available data from April to December) to enable us capture mortality around the period of cART introduction. The remaining 10 calendar intervals were 2 -year periods each. In sensitivity analyses, we investigated trends over time in ASMR among HIV-infected individuals according to antiretroviral drug uptake (ever vs. never), use of triple-drug cART at treatment initiation (yes vs. never), both compared to uninfected individuals. We calculated the mortality rate ratio as an estimate of the relative risk comparing HIV-infected and uninfected individuals by dividing the ASMRs of HIVinfected individuals by that of uninfected individuals. The $95 \%$ confidence intervals $(\mathrm{CI})$ for the mortality rates and rate ratios were calculated by Normal approximation assuming a Poisson distribution [33, 34]. Population figures for the Canadian standard population were obtained from Statistics Canada [35]. As a sensitivity analysis for comparison purposes only, we repeated the standardization of the mortality rates using the latest available Canadian censual population (2011) [35].

Comparisons between groups were performed using Chi-square test or Fisher exact test for categorical variables and Kruskall-Wallis test for continuous variables. Test of trend over time were performed using Kendall rank correlation. Statistical significance is defined at a 0.05 level. All data manipulation and statistical analyses were performed using SAS 9.4 (Cary NC, USA) and R Statistical Program, version 3.2.2 (Vienna, Austria).

\section{Results}

\section{Participant characteristics}

From April 1996 to December 2012, 13,729 HIVinfected and 510,313 uninfected individuals - a combined 524,042 persons - contributed a follow-up of 108,990 PYs (median: $7.22\left[25^{\text {th }}, 75^{\text {th }}\right.$ percentile: 2.96 , 12.97] years per person) and 5,511,160 PYs (median: $12.70[4.76,16.75]$ years per person) of observation, respectively to the analysis. The baseline characteristics of the study participants are described in Table 2. Compared to uninfected individuals, HIV-infected individuals were more likely to be older at cohort entry (median age: 38 vs 36 years, $p<0.001$ ) and more likely to be male ( $80 \%$ vs. $50 \%, p<0.001$ ). Roughly one-quarter of HIVinfected individuals had no record of HIV treatment initiation. Among those who have ever received ART, approximately $37 \%$ initiated therapy with an AIDSdefining CD4 count $\left(<200\right.$ cells $\left./ \mathrm{mm}^{3}\right)$.

\section{Mortality during follow-up}

During the approximately 17 years of observation, a total of 3401 HIV-infected (25\%) and 47,647 uninfected individuals (9\%) died. Compared to uninfected individuals, HIV-infected individuals were more likely to die young (median age: 46 vs 80 years, $p<0.001$ ), with approximately $75 \%$ of the deaths occurring

Table 2 Characteristics of study participants

\begin{tabular}{|c|c|c|c|c|c|c|}
\hline \multirow[t]{2}{*}{ Characteristics } & \multicolumn{3}{|c|}{ Entire sample, n (\%) } & \multicolumn{3}{|l|}{ Dead, n (\%) } \\
\hline & $\begin{array}{l}\text { HIV+ } \\
(N=13729)\end{array}$ & $\begin{array}{l}\text { HIV- } \\
(N=510313)\end{array}$ & $p$-value & $\begin{array}{l}\text { HIV+ } \\
(N=3401)\end{array}$ & $\begin{array}{l}\text { HIV- } \\
(N=47647)\end{array}$ & $p$-value \\
\hline Age at study entry, median (Q1, Q3) years & $38(32,46)$ & $36(24,50)$ & $<0.001$ & $41(34,49)$ & $71(59,78)$ & $<0.001$ \\
\hline Age at death, median (Q1, Q3) years & & & & $46(39,55)$ & $80(69,87)$ & $<0.001$ \\
\hline \multicolumn{7}{|l|}{ Sex } \\
\hline Male & $11017(80.25)$ & $256440(50.25)$ & $<0.001$ & $2716(79.86)$ & $24394(51.20)$ & $<0.001$ \\
\hline Female & $2712(19.75)$ & $253873(49.75)$ & & $685(20.14)$ & $23253(48.80)$ & \\
\hline Follow-up time, median $(\mathrm{Q} 1, \mathrm{Q} 3)$ years & $7.22(2.96,12.97)$ & $12.70(4.76,16.75)$ & $<0.001$ & $3.91(1.16,7.60)$ & $8.42(4.25,12.58)$ & $<0.001$ \\
\hline \multicolumn{7}{|l|}{ Antiretroviral therapy ever? } \\
\hline Yes & $10165(74.04)$ & & & $2377(69.89)$ & & \\
\hline No & $3564(25.96)$ & - & & $1024(30.11)$ & - & \\
\hline
\end{tabular}

Legend: Q1, $25^{\text {th }}$ percentile; Q3, $75^{\text {th }}$ percentile 
before or at 55 years of age compared to 87 years among uninfected individuals (Table 2). Table 3 shows the number of deaths and crude mortality rates by age, sex and cause of death. The proportion of deaths among HIV-infected women $(25.3 \%)$ was not significantly different from that for infected men $(24.7 \%)(p$ $=0.529$ ). Conversely, the proportion of deaths among uninfected women was lower compared to uninfected men $(9.2 \%$ vs. $9.5 \%, p<0.001)$.

\section{Causes of death}

Figures 1 and 2 show the distribution and annual changes in the proportion of deaths across causes among the study participants during the observation period. Although HIV/AIDS-related deaths accounted for $50 \%$ of the total deaths among HIV-infected individuals during follow-up (Fig. 1), the proportion of deaths from HIV/ AIDS-related causes dropped from 79\% in 1996 to $27 \%$ by $2012(p<0.001)$ (Fig. 2). Overall, the top non-HIV/ AIDS-related causes of death during the study follow-up in decreasing order are: drug abuse and overdose (11.2\%), cancers (8.5\%), CVD (7.0\%), and hepatic and liver diseases (4.4\%). The majority of deaths classified under 'other causes' included deaths from unknown causes and a myriad of other conditions. This cause of death category accounted for $7.9 \%$ and $13.1 \%$ of mortality among HIV-infected and uninfected individuals respectively.

Among HIV-infected individuals, the proportion of deaths due to HIV/AIDS decreased significantly over time since $1996(p<0.001)$, while those from non-HIV/ AIDS-related causes either remained stable or increased over time (Fig. 2). In 1996, CVD and non-AIDS-defining cancer accounted for a combined $<2 \%$ of deaths among HIV-infected individuals compared to $29 \%$ in 2012 ( $p<$ $0.05)$. Non-AIDS-defining cancers which accounted for $<1.0 \%$ of the deaths in 1996 have recently emerged to become the leading non-HIV/AIDS-related cause of death, accounting for $17 \%$ of all deaths among infected individuals by $2012(p<0.001)$. Among deaths attributable to non-AIDS defining cancers, lung cancer was the most commonly observed cancer type in both HIVinfected and uninfected individuals. In decreasing order, this was followed by cancer of the liver, colon, pancreas, anus, rectum, stomach and prostate among HIV-infected individuals; and colon, breast, prostate, pancreas, bladder, esophagus, stomach and ovarian cancer among uninfected individuals.

Among uninfected individuals, CVD (32\%) and cancers $(29 \%)$ were the most common accounting for over $60 \%$ of the deaths during follow-up. In terms of trend, the proportion of deaths from CVD decreased over time $(p<0.001)$, while deaths due to cancer have increased ( $p$ $=0.02$ ), overtaking CVD as the leading cause of death in more recent years (Fig. 2). Consequently, in both HIVinfected and uninfected individuals, our results demonstrate that cancers are now the leading non-HIV/AIDSrelated cause of death. Compared to HIV-infected individuals where deaths due to drug abuse and overdose was among the leading cause of death, this category accounted for the least proportion of deaths among uninfected individuals during follow-up.

\section{Changes in age-standardized mortality rate}

Figures 3 and 4 describes the changes over time in the age-standardized all-cause and cause-specific mortality rates, by HIV status. Among HIV-infected individuals, the all-cause ASMR decreased from 126.75 (95\% CI: $84.92-168.57)$ per 1000 population in 1996 , to 21.29 (95\% CI: $17.79-24.79)$ in 2011-2012 $(p<0.001$ for trend). In the uninfected population, the all-cause ASMR changed over similar time period, from 7.97 (95\% CI: 7.61-8.33) per 1000 population to 6.87 (95\% CI: 6.70-7.04), respectively ( $p<0.001$ for trend) (Fig. 3a). This represents an $83 \%$ drop in all-cause mortality rate from 1996 to 2011-2012 era among HIV-infected individuals compared to a $14 \%$ drop among uninfected individuals. The age-adjusted relative risk of death in HIV-infected compared to uninfected individuals decreased from 15.90 (95\% CI: 11.40-22.19) in 1996 to 3.10 (95\% CI: 2.63-3.66) in the 2011-2012 era, representing a $81 \%$ reduction in the relative risk of mortality over time. When stratified by sex, the relative risk of death comparing infected to uninfected individuals was similar in males and females as of 1996 (13.70 vs 13.72). By the 2011-2012 era, the relative risk of death comparing HIV-infected and uninfected men was 2.33 (95\% CI: 1.94-2.80), whereas it was 4.65 (95\% CI: 3.356.45) among HIV-infected compared to uninfected women (Fig. 3b, 3c).

The ASMR from HIV/AIDS-related deaths decreased significantly from 103.85 in 1996 to 6.72 per 1000 population in the 2011-2012 eras $(p<0.001$ for trend), representing a $94 \%$ reduction in death rate from HIV/AIDSrelated causes (Fig. 4a). Over the study's observation period, significant reductions in mortality rates among HIV-infected individuals were also observed for mortality from hepatic and liver disease, as well as from drug abuse and overdose. Although the proportion of deaths attributable to CVD and non-AIDS-defining cancers significantly increased over time $(p<0.05)$ among HIVinfected individuals (Fig. 2a), the mortality rates from CVD and cancer decreased over time (Fig. 4b, 4f), albeit not significantly $(p>0.05)$. There was a statistically significant increase over time in mortality rates and proportion of deaths attributable to neurological disorders (Figs. 2a and 4j; $p<0.05$ ). For chronic respiratory diseases, renal diseases, other infectious and parasitic 


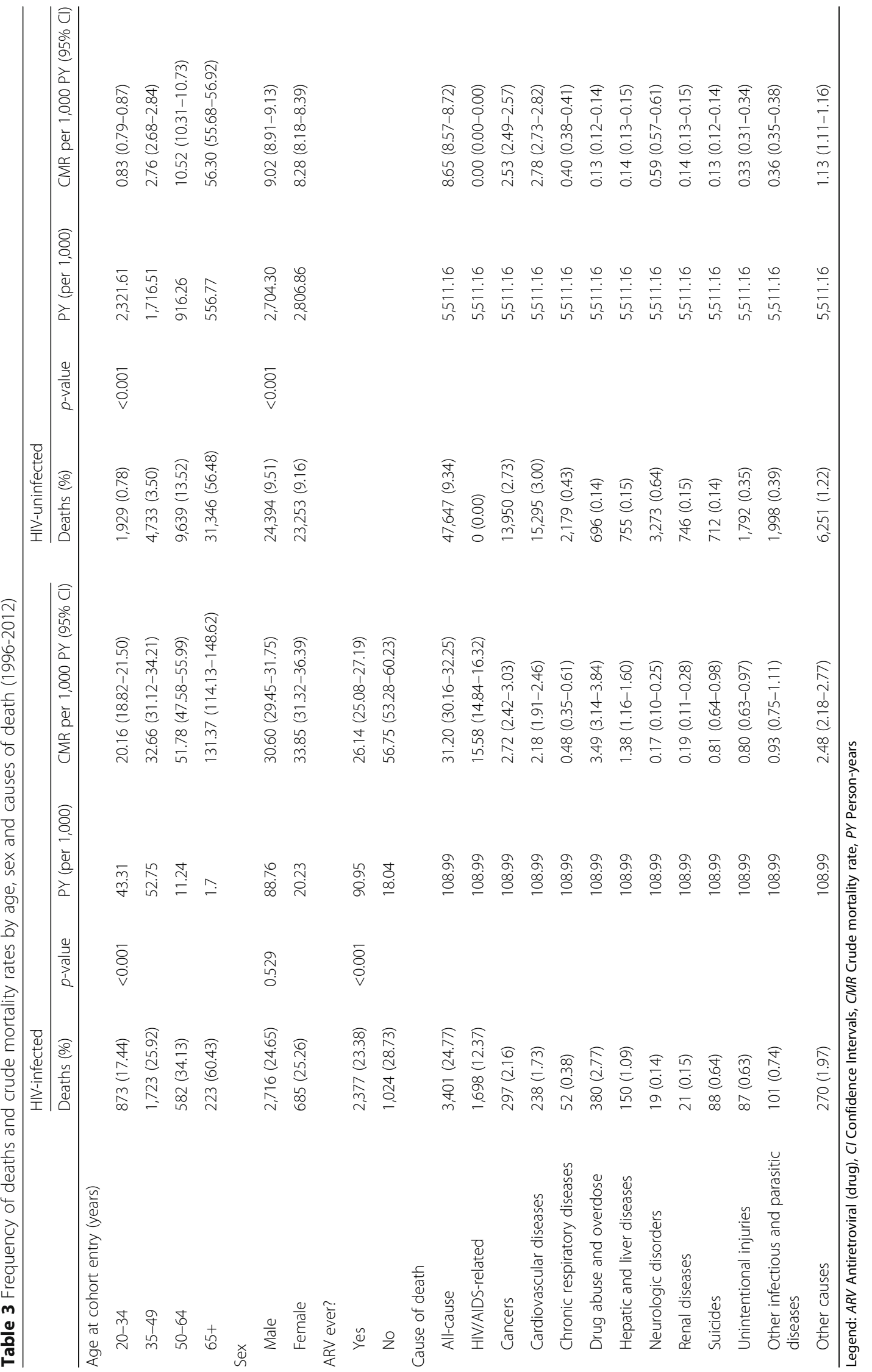




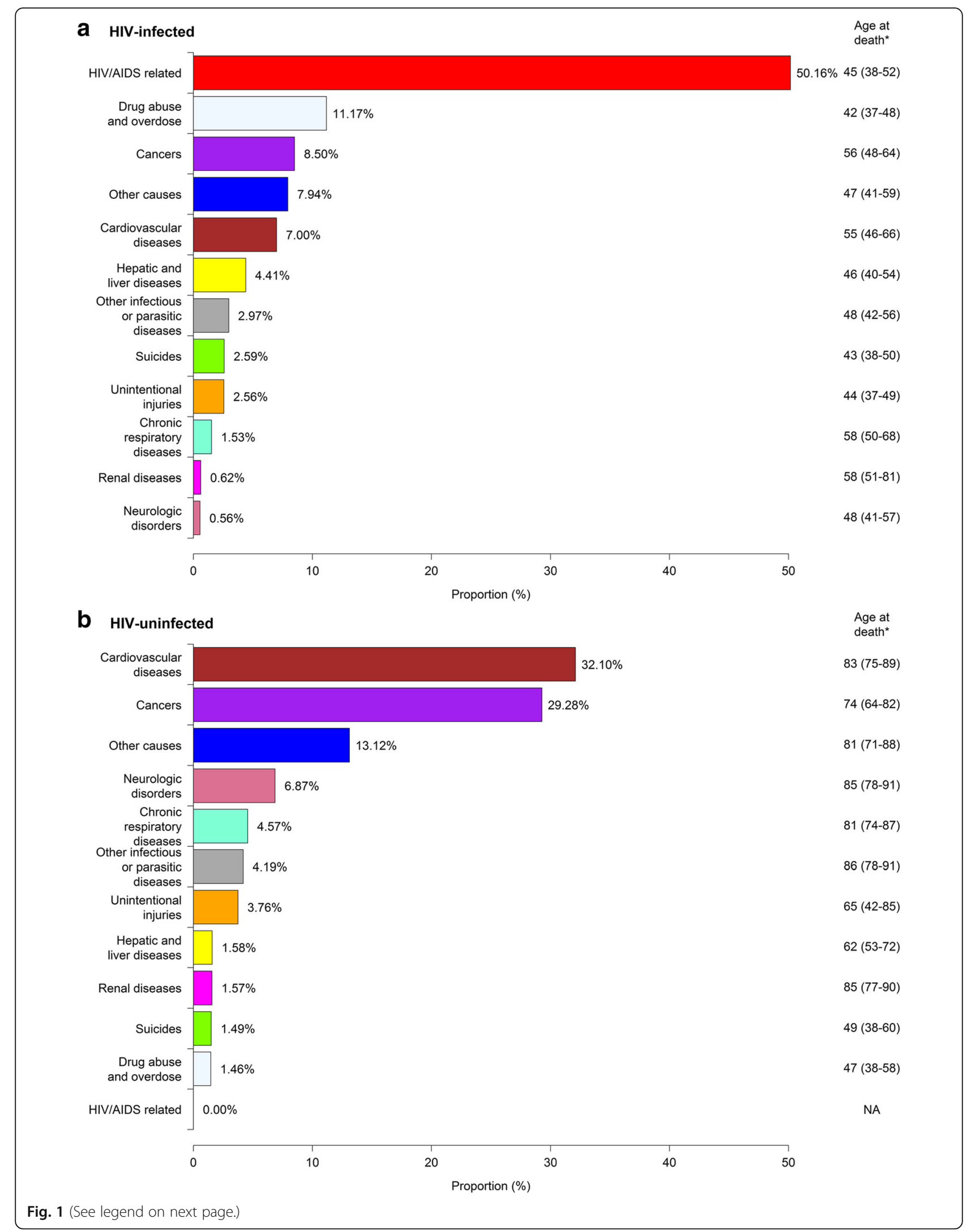


(See figure on previous page.)

Fig. 1 Overall distribution of the proportion of deaths by causes and by HIV status in British Columbia, during 1996-2012. Legend: *, Values are in the format 'median age $\left(25^{\text {th }}\right.$ percentile- $75^{\text {th }}$ percentile)' years; Note: The 'cancer' category in Fig. 1a excludes deaths attributable to Kaposi sarcoma, cervical cancer and Non-Hodgkin's lymphoma, as these have been accounted for within HIV/AIDS-related deaths. a HIV-infected, b HIV-uninfected

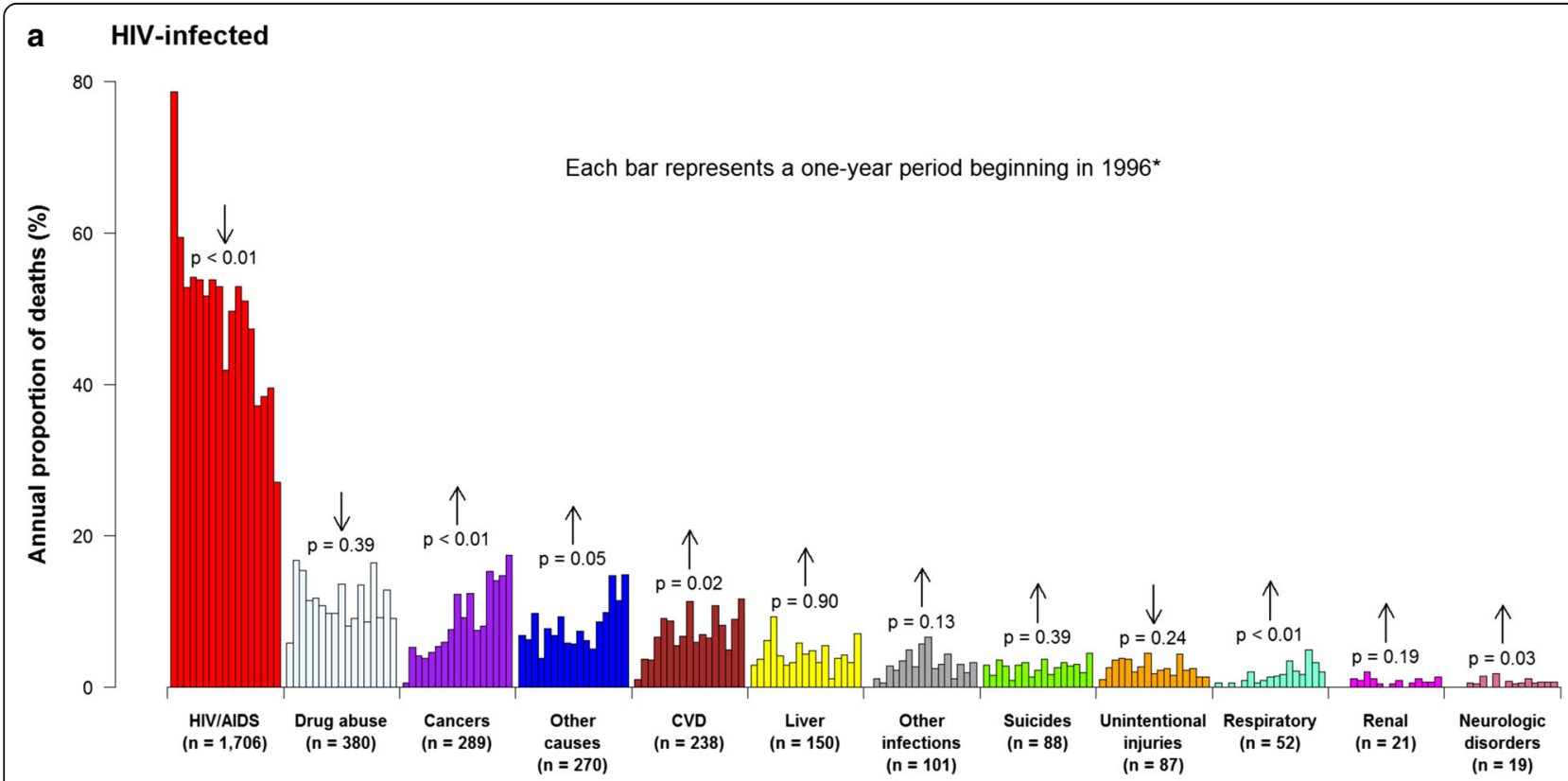

\section{b HIV-uninfected}

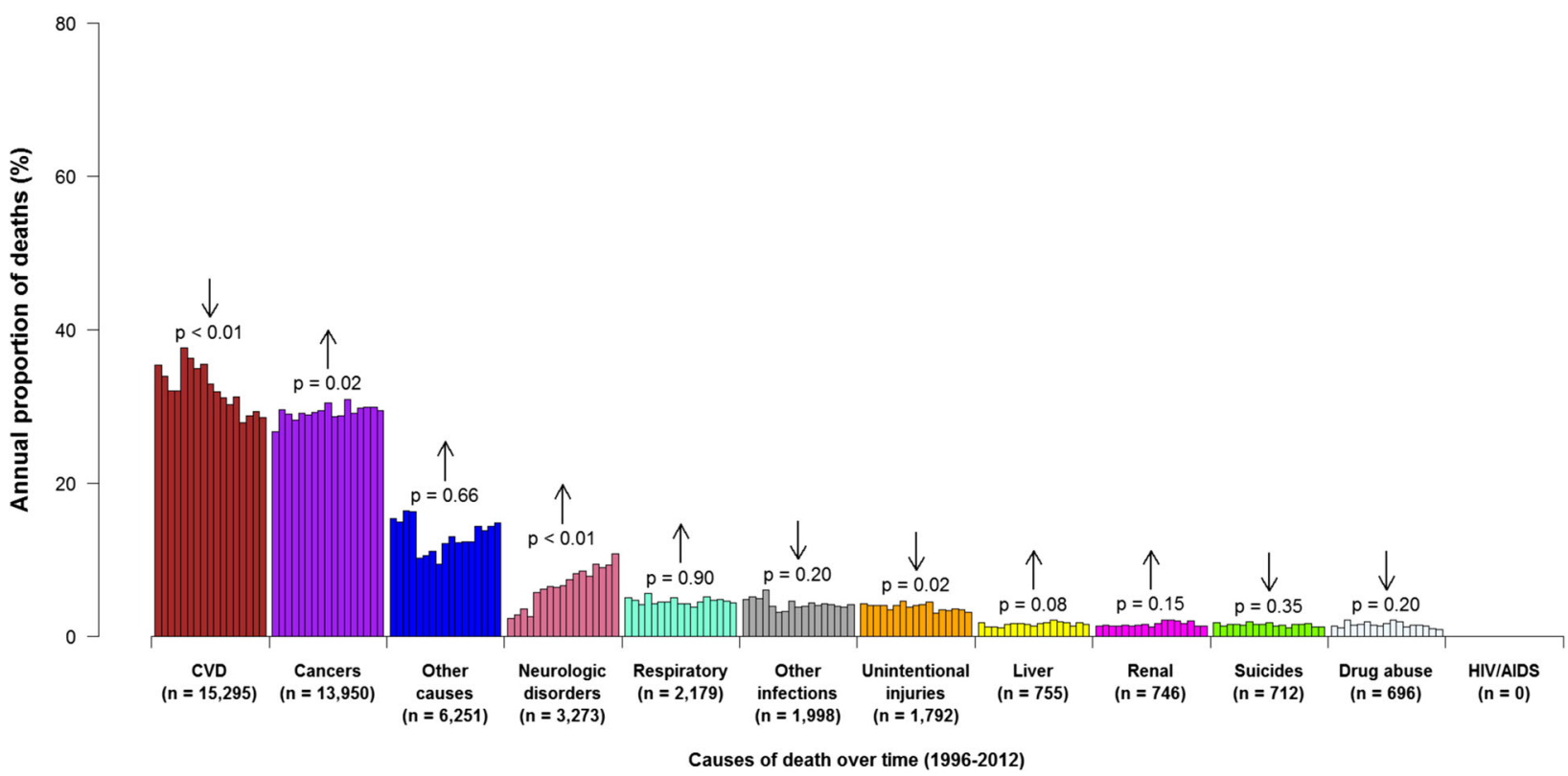

Fig. 2 Annual changes in the proportion of deaths by causes and by HIV status in British Columbia, during 1996-2012. Legend: CVD, Cardiovascular diseases; *, Each bar in the figure represents a one-year period beginning in 1996 (except for the first bar - 1996 -, which is nine months long); Note: The 'cancer' category in Fig. 2a excludes deaths attributable to Kaposi sarcoma, cervical cancer and Non-Hodgkin's lymphoma, as these have been accounted for within HIV/AIDS-related deaths. a HIV-infrcted, b HIV-uninfected 


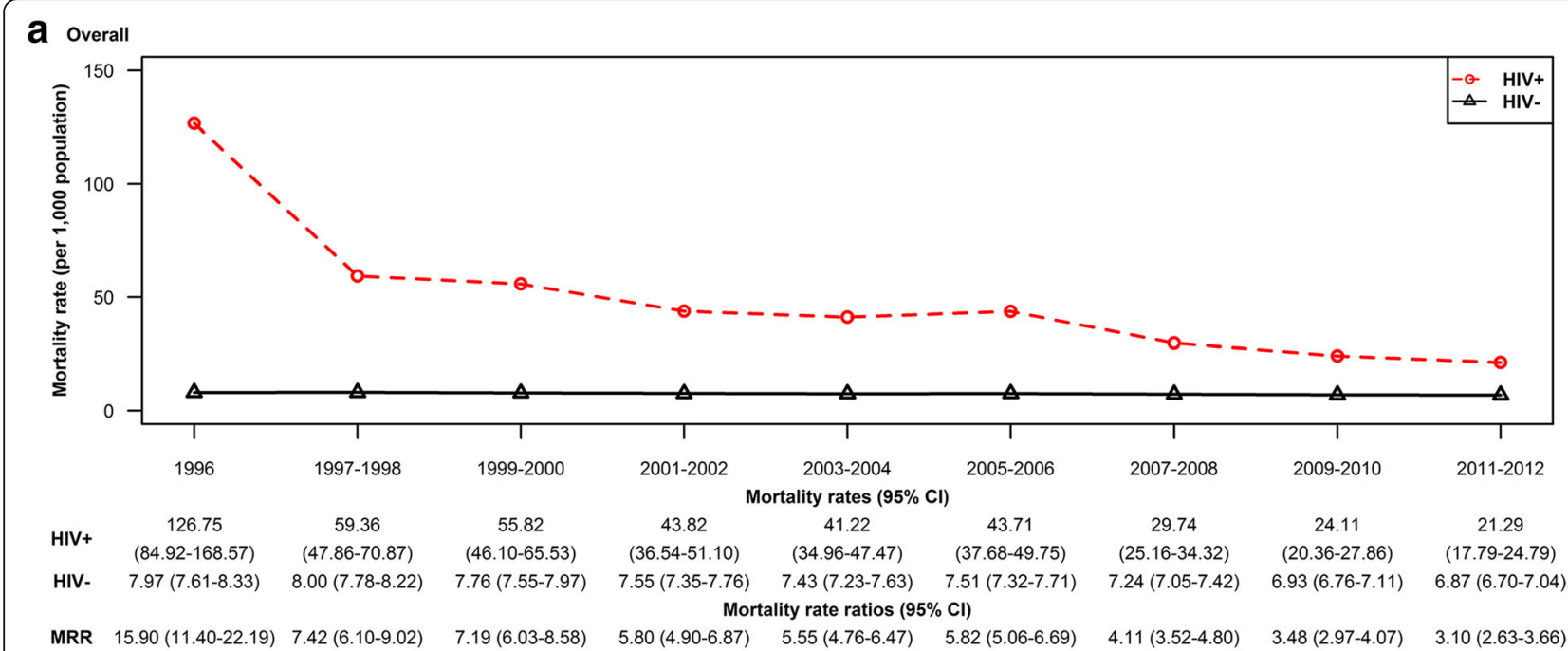

b Male-only

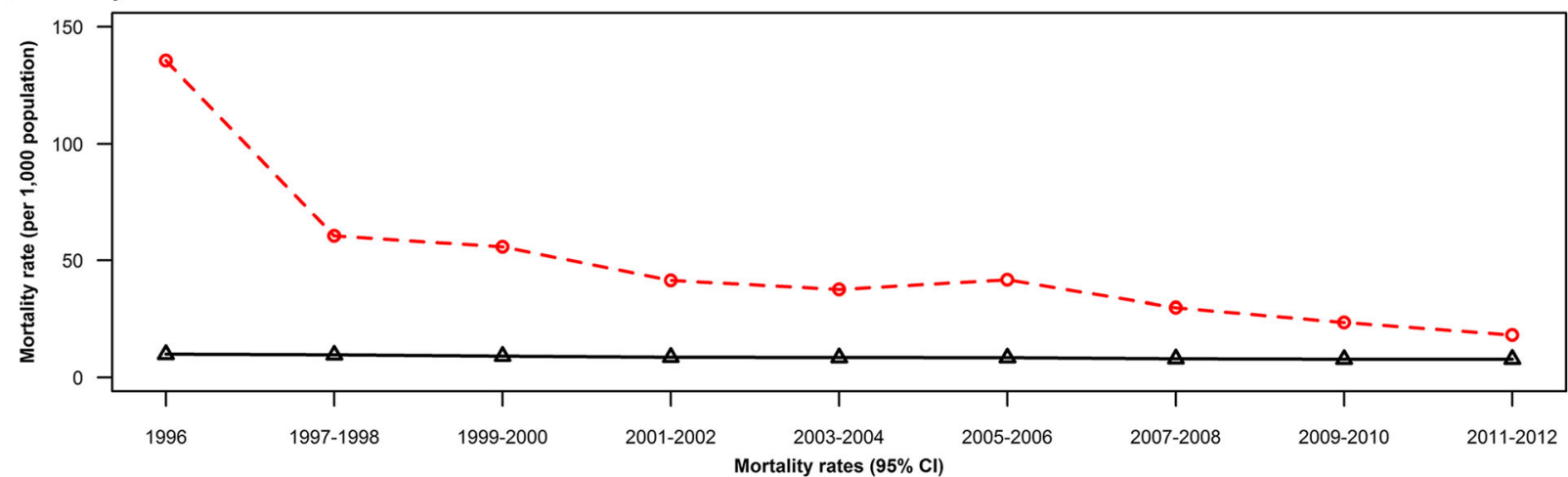

\begin{tabular}{|c|c|c|c|c|c|c|c|c|c|}
\hline HIV+ & $\begin{array}{c}135.54 \\
(84.05-187.04)\end{array}$ & $\begin{array}{c}60.48 \\
(46.40-74.57)\end{array}$ & $\begin{array}{c}55.78 \\
(44.09-67.48)\end{array}$ & $\begin{array}{c}41.40 \\
(32.97-49.83)\end{array}$ & $\begin{array}{c}37.51 \\
(30.68-44.34)\end{array}$ & $\begin{array}{c}41.62 \\
(35.01-48.24)\end{array}$ & $\begin{array}{c}29.76 \\
(24.24-35.27)\end{array}$ & $\begin{array}{c}23.52 \\
(19.18-27.86)\end{array}$ & $\begin{array}{c}18.12 \\
(14.88-21.37)\end{array}$ \\
\hline HIV- & $9.90(9.28-10.51)$ & $9.64(9.28-10.00)$ & $9.11(8.77-9.46)$ & $8.62(8.30-8.95)$ & $8.48(8.17-8.80)$ & $8.42(8.11-8.72)$ & $7.99(7.70-8.28)$ & $7.77(7.49-8.04)$ & $7.78(7.51-8.05)$ \\
\hline & \multicolumn{9}{|c|}{ Mortality rate ratios $(95 \% \mathrm{Cl})$} \\
\hline MRR & $13.70(9.32-20.13)$ & $6.27(4.96-7.94)$ & $6.12(4.95-7.58)$ & $4.80(3.90-5.90)$ & $4.42(3.67-5.32)$ & $4.94(4.20-5.82)$ & $3.72(3.08-4.50)$ & $3.03(2.51-3.65)$ & $2.33(1.94-2.80)$ \\
\hline
\end{tabular}

C Female-only

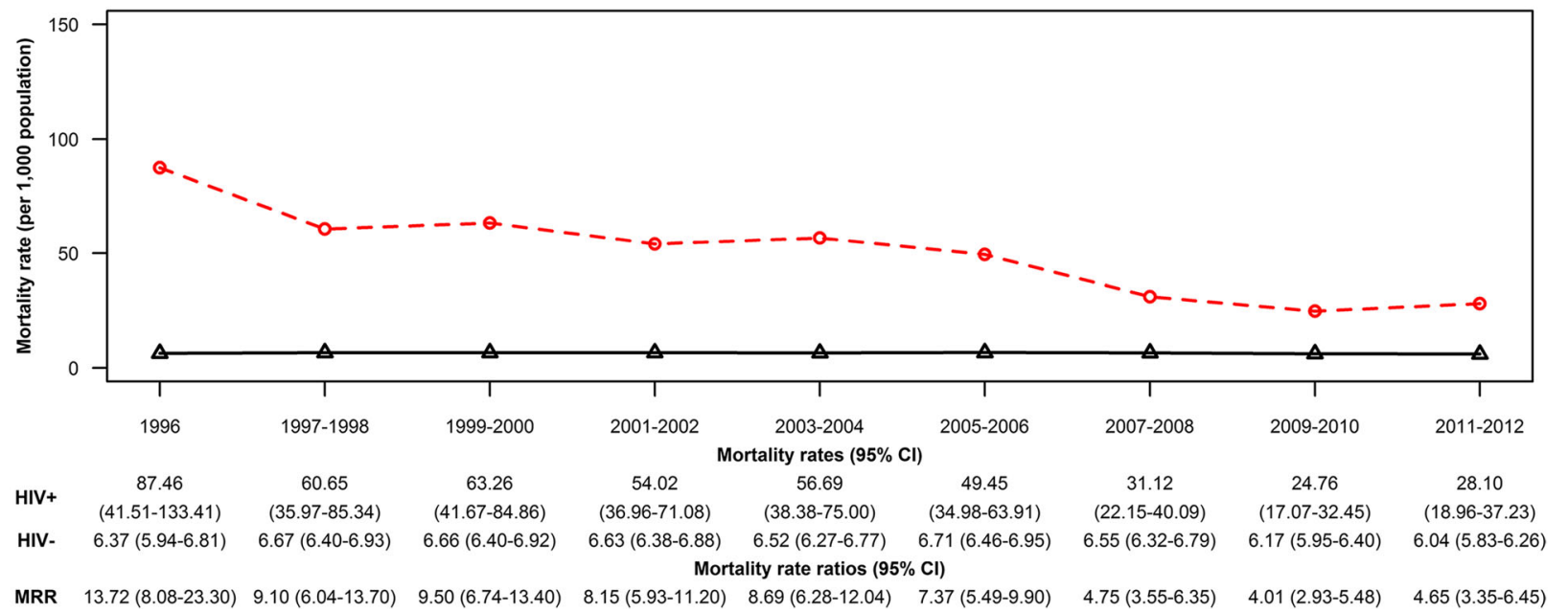

Fig. 3 Changes over time in all-cause age-standardized mortality rates, overall and by HIV status and sex in British Columbia, during 1996-2012. Legend: $\mathrm{Cl}$, Confidence interval; MRR, Mortality rate ratio. a Overall, b Male-only, c Female only 


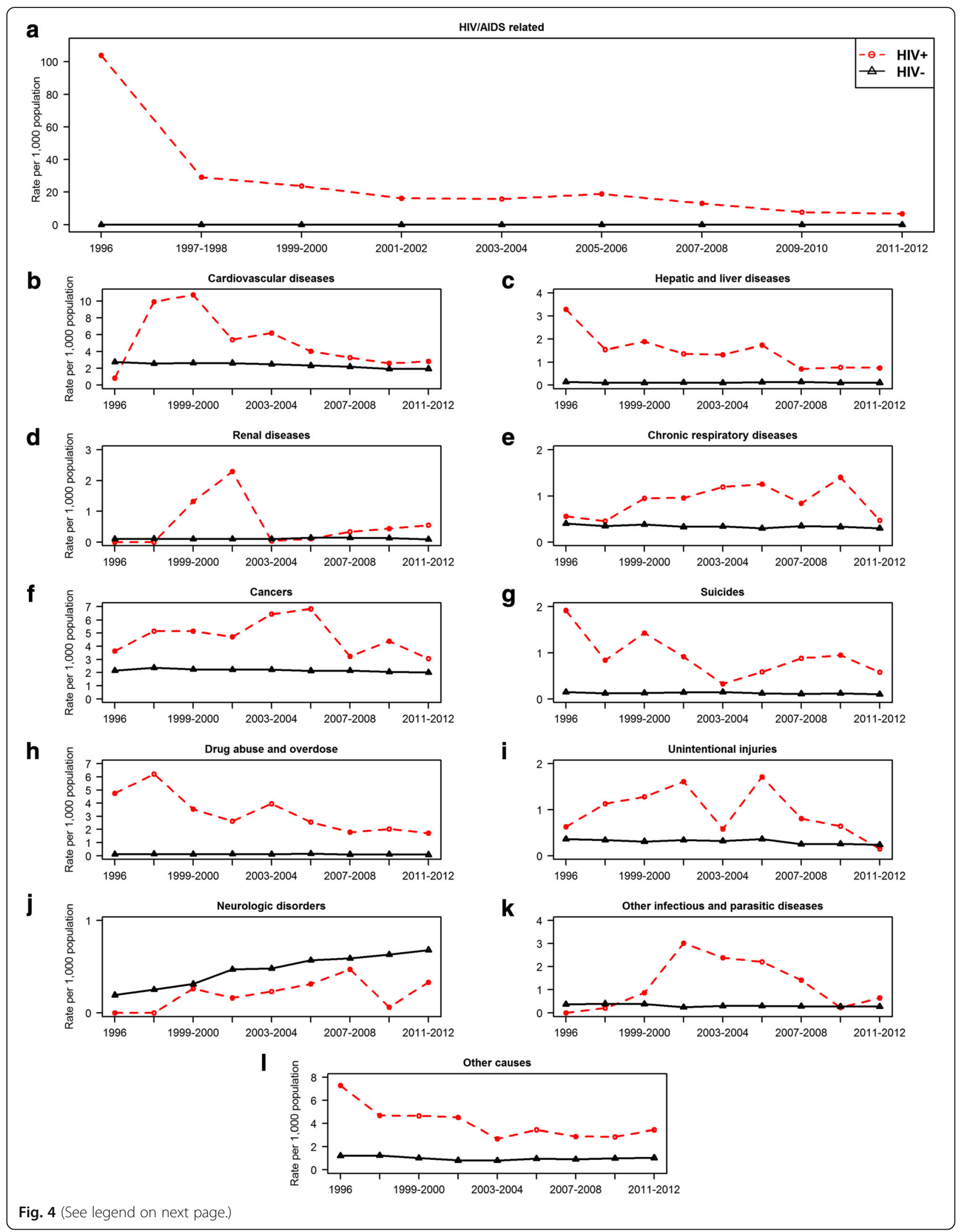


(See figure on previous page.)

Fig. 4 Changes over time in cause-specific age-standardized mortality rates, by HIV status in British Columbia, during 1996-2012. Legend: The 'cancer' mortality line graph for HIV-infected individuals (Fig. 4f, red line) excludes deaths attributable to Kaposi sarcoma, cervical cancer and Non-Hodgkin's lymphoma, as these have been accounted for within HIV/AIDS-related deaths. a HIV/AIDS related, b cardiovascular diseases, c Hepatic and liver diseases, $\mathbf{d}$ Renal diseases, e Chronic respiratory diseases, $\mathbf{f}$ Cancers, $\mathbf{g}$ Suicides, $\mathbf{h}$ Drug abuse and overdose, i unintentional injuries, j Neurologic disorders, $\mathbf{k}$ Other infectious and parasitic diseases, I Other causes

diseases deaths, mortality rate increases were observed but this was not significant.

Among uninfected individuals, statistically significant mortality rate reductions were observed over time for deaths attributable to CVD, cancers, chronic respiratory diseases, suicides, unintentional injuries and other infectious and parasitic diseases; however mortality rates attributable to neurologic disorders increased significantly over time.

\section{Sensitivity analyses}

Although we observed slightly higher ASMRs (data not shown) when we standardized rates using a 2011 Canadian censual population compared to the main analyses that used a 1991 censual population, the overall trends remained unchanged. The slight increase in mortality rates is likely because the 2011 censual population has a higher proportion of individuals in older age groups than the 1991 population. In separate analyses stratified by antiretroviral therapy uptake (ever vs. never) and initiation of therapy with triple-drug cART (yes vs. never on therapy), we observed significant mortality rate reductions over time across all groups (Figs. 5 and 6). During the analytic period, individuals who were never on ART had mortality rates ranging from 1.4 to almost 5 times higher than among those ever on ART or those initiating treatment with triple-drug cART. Of note, $92 \%$ of individuals ever on ART in this study initiated therapy on a triple-drug cART.

\section{Discussion}

Since cART introduction in 1996, this is the first population-based study in Canada to characterize changes in mortality and causes of death among persons living with HIV infection as compared to uninfected individuals from the same geographical and health care setting. Compared to uninfected individuals, our result demonstrates that the causes of death among HIVinfected individuals in $\mathrm{BC}$ have changed dramatically over time. We observed significant mortality rate reductions in all-cause, HIV/AIDS-related, drug abuse and overdose, and liver disease mortality among people living with HIV in the period from 1996 to 2012. Despite the remarkable decline in mortality from HIV-related causes, HIV/AIDS is still the leading cause of death

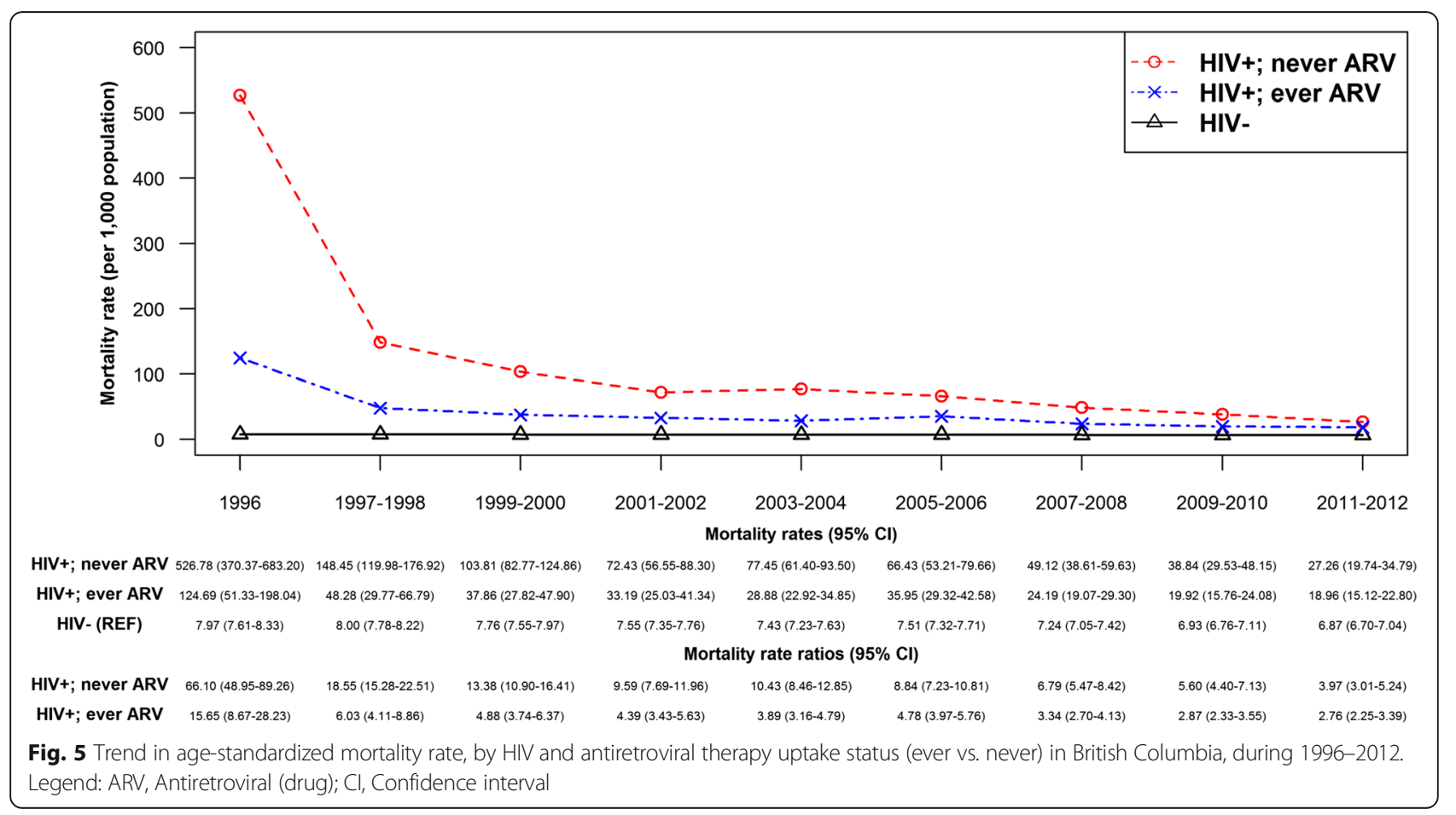




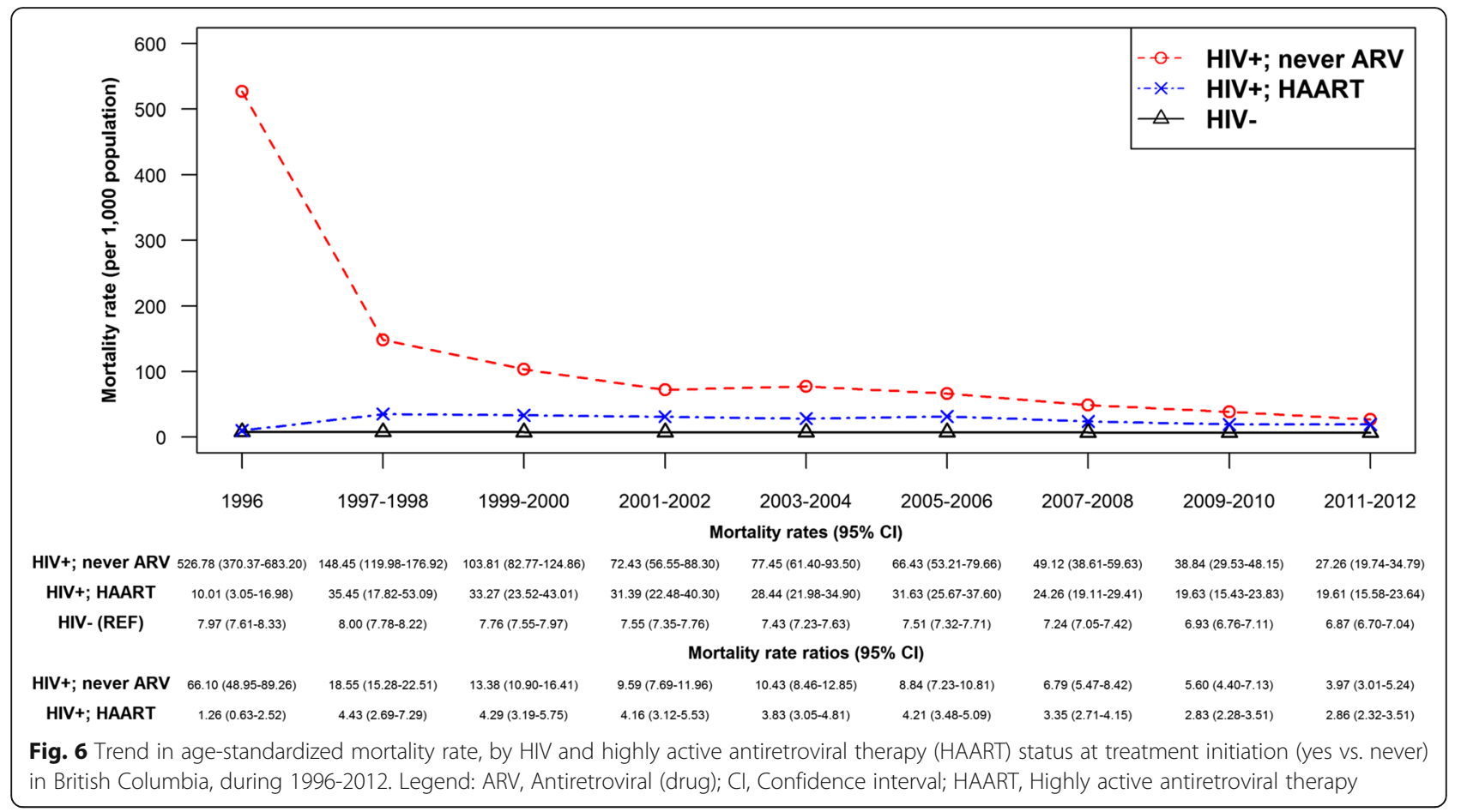

among HIV-infected individuals and the relative risk of death remains in excess of that for uninfected individuals. Relative to other causes of death, the proportion of total mortality attributable to non-AIDS-defining cancer and CVD has increased among HIV-infected individuals since cART introduction, however, this did not necessarily translate into a trend of increasing mortality rates from these causes; a finding that may be likely due to the overall increased survival in the population. In both HIV-infected and uninfected individuals, we observed significant increases over time in mortality rates from neurologic disorders.

The overall proportion of deaths due to HIV/AIDS-related causes in our study (50.2\%) was comparable to those reported from Spain (40.4\%) [36], Italy (41.4\%) [16], Denmark (44.4\%) [37], England and Wales (46.0\%) [38], France (47.3\%) [39], USA (51.4\%) [15] and from multinational cohort collaborations such as Antiretroviral Therapy Cohort Collaboration (49.6\%) [14], but higher than that reported in the Data collection on Adverse events of Anti-HIV Drugs [D:A:D] study (28.7\%) [40]. While our overall findings are broadly consistent with the mortality declines and cause of death trends presented in previous studies of HIV-infected individuals from other settings [13-16, 38, 40, 41]; variations in the range of such estimates may exist across studies and are likely due to heterogeneity in the population (e.g., by age, sex, CD4 levels, cART history, underlying clinical characteristics, ethnicity), differences in the observation period, or the coding scheme for causes of death categories. In sensitivity analysis stratified by ART uptake (ever vs. never), we observed a better mortality prognosis among those who had ever been treated with ART, thus demonstrating the benefit associated with ART. This is supported by a recent BC study among HIV-infected individuals receiving cART since 2001 which demonstrated that cART initiation was independently associated with reduced mortality [21].

The current study reflects major changes since the introduction of cART in terms of non-HIV/AIDS-related causes; in 1996, only $21 \%$ of the deaths among HIVinfected individuals were attributable, as compared to $73 \%$ by 2012 . Our results confirm two recent reports suggesting that non-AIDS-defining cancers are currently the leading non-HIV/AIDS-related cause of death among HIV-infected individuals [40, 42]. Similarly, we observed that cancers have also recently overtaken CVD to become the principal cause of death among the uninfected population. Like the D:A:D study [40] but unlike a report from the HIV Outpatient Study [15], we observed a statistically significant mortality rate decrease from hepatic and liver disease deaths. Contrary to a finding among HIV-infected hemophiliacs in Canada [43], liver disease is an important cause of death especially among individuals co-infected with HIV and hepatitis C virus [44], although not the main non-HIV/AIDS-related cause of death in the current study. The observed increase in mortality rates attributable to neurologic disorders is likely a reflection of the increased longevity in both populations. 
Our results indicating that HIV-infected individuals continue to have a mortality risk ratio that is decreasing as time passes but remains approximately three times more than in uninfected individuals as of 2011-2012 is supported by comparable findings from other studies that have compared mortality rates among persons with and without HIV infection [37, 45]. We suspect the continuing high relative risk of death among HIV-infected, compared to uninfected individuals may in part be explained by the higher prevalence of behavioral risk factors such as smoking, alcohol abuse and other lifestyle factors that are more common among HIV-infected individuals and predisposes them to higher mortality risk compared to uninfected individuals.

Readers should interpret our findings in light of the potential strengths and limitations of the study. The HIV-infected cohort includes the vast majority of all known HIV-infected adults in BC, irrespective of whether they had ever received cART. Despite universal access to HIV treatment in BC, approximately $25 \%$ of HIV-infected individuals had no record of HIV treatment initiation during this study (1996 to 2012). Reassuringly, the rates have declined substantially with the implementation of the Treatment as Prevention strategy in BC [46-48], as in a 2008 study we found that $40 \%$ of those who died from HIV did not access treatment [49]. Our uninfected cohort includes randomly sampled BC residents who accessed the same universal health care system as the HIV-infected participants, thus minimizing potential selection bias that may arise from using an external comparison group. Unlike most clinic-based cohorts $[11,13,16,36,39,40,50]$, the relatively large, linked and population-based nature of the COAST study is unique to $\mathrm{BC}$ and has allowed us to ascertain mortality and cause of death information for all study participants through the same source - the BC Vital Statistics Agency -[31], which is the provincial office that collects vital statistic records in $\mathrm{BC}$. However, since this dataset does not capture deaths to $\mathrm{BC}$ residents that occur outof-province, such deaths were unaccounted for in our analyses. While we suspect this number is likely small, it also will have affected the HIV-infected and uninfected cohorts equally. Finally, our cause of death assessment is limited by the accuracy of the ICD-9/10 coding used for attribution of the underlying cause of death; and the study as a whole, by unmeasured confounding due to its observational nature.

\section{Conclusion}

To sum up, our results suggest that significant improvements have been made in reducing mortality over time from HIV/AIDS-related and several non-HIV/AIDS-related causes of death among people living with HIV. Despite this progress, HIV-infected individuals still have excess mortality risk compared to their uninfected counterparts. Additional efforts are needed to promote effective risk factor management and appropriate screening measures among people living with HIV. Ongoing monitoring of mortality trends by causes will be important and will provide the necessary data to enable us optimally target our efforts at the conditions that influence morbidity and mortality outcomes. Ultimately, in both HIV-infected and uninfected populations, the management of cancers and CVD as well as their known risk factors will be key in improving overall survival outcomes.

\section{Abbreviations}

ART: Antiretroviral therapy; ARV: Antiretroviral (drug); ASMR: Age-standardized mortality rate; BC: British Columbia; BCCFE: BC Centre for Excellence in HIV/ AIDS; CART: Combination antiretroviral therapy; Cl: Confidence interval; COAST: Comparative Outcomes And Service Utilization Trends study; CVD: Cardiovascular disease; D:A:D: Data collection on Adverse events of Anti-HIV Drugs study; ICD: International Classification of Diseases; MRR: Mortality rate ratio; PY: Person-years

\section{Acknowledgements}

The authors would like to thank the BCCfE, BC Ministry of Health, BC Vital Statistics Agency, and the institutional data stewards for granting access to the data, and Population Data BC, for facilitating the data linkage process. The COAST steering committee includes: Julio Montaner, Robert Hogg, Oghenowede Eyawo, Mark Hull, Jeannie Shoveller, David Moore, Paul Sereda and Viviane Lima.

\section{Funding}

COAST is funded by the Canadian Institutes of Health Research, through an Operating Grant (\#130419), a Foundation Award to RSH (\#143342) and support from the BCCFE. The funders had no role in the study design, analysis, interpretation of the data, drafting of the manuscript or in the decision to submit for publication.

\section{Availability of data and material}

The data used for this study is not publicly available. For further information on the data and materials used in this study, please contact the corresponding author

\section{Authors' contributions}

Study concept and design: OE; acquisition of data: OE, MWH, HS, JSGM, RSH; analysis and interpretation of data: $\mathrm{OE}, \mathrm{CF}, \mathrm{AN}, \mathrm{MWH}, \mathrm{PS}, \mathrm{VL}, \mathrm{RSH}$; drafting of the manuscript: $\mathrm{OE}$; critical revision of the manuscript for important intellectual content and for final approval: OE, CF, MWH, AN, HS, PS, VL, JS, DM, JSGM, RSH; acquisition of funding: OE, VL, JSGM, RSH. All authors have read and approved the final version.

\section{Competing interests}

OE is supported by a Canadian Institutes of Health Research doctoral award. MWH has received grant support from the National Institute on Drug Abuse (NIDA R01DA031043-01) and has received honoraria for speaking engagements and/or consultancy meetings from the following: Bristol Myers Squibb, Gilead, Merck, Ortho-Janssen, Pfizer, Sunovion, Vertex Pharmaceuticals and Viiv. JSGM is supported with grants paid to his institution by the British Columbia Ministry of Health and by the US National Institutes of Health (R01DA036307). He has also received limited unrestricted funding, paid to his institution, from Abbvie, Bristol-Myers Squibb, Gilead Sciences, Janssen, Merck, and ViiV Healthcare. RSH has held grant funding in the last 10 years from the National Institutes of Health, Canadian Institutes of Health Research, Health Canada, Merck, and the Social Sciences and Humanities Research Council of Canada. The remaining authors have no disclosures to declare. 


\section{Ethics approval and consent to participate}

The COAST study has received approval from the University of British Columbia/Providence Health Care Research Ethics Board (\#H09-02905) and Simon Fraser University Office of Research Ethics (\#2013 s0566). The study complies with the BC Freedom of Information and Protection of Privacy Act (FIPPA) and did not require informed consent as it is conducted retrospectively for research and statistical purposes only using anonymized data.

\section{Disclaimer}

All inferences, opinions, and conclusions drawn in this manuscript are those of the authors, and do not reflect the opinions or policies of the data stewards or the funders.

\section{Author details}

${ }^{1}$ British Columbia Centre for Excellence in HIV/AIDS, St. Paul's Hospital, 608-1081 Burrard Street, Vancouver, BC, Canada. ${ }^{2}$ Faculty of Health Sciences, Simon Fraser University, Burnaby, BC, Canada. ${ }^{3}$ DataClever Consulting Inc., Vancouver, BC, Canada. ${ }^{4}$ British Columbia Centre for Disease Control, Vancouver, BC, Canada. ${ }^{5}$ School of Population and Public Health, University of British Columbia, Vancouver, BC, Canada. 'D Department of Medicine, University of British Columbia, Vancouver, BC, Canada.

\section{Received: 30 August 2016 Accepted: 8 February 2017} Published online: 27 February 2017

\section{References}

1. Hogg RS, Heath KV, Yip B, Craib KJ, O'Shaughnessy MV, Schechter MT, Montaner JS. Improved survival among HIV-infected individuals following initiation of antiretroviral therapy. JAMA. 1998;279(6):450-4.

2. Palella Jr FJ, Delaney KM, Moorman AC, Loveless MO, Fuhrer J, Satten GA, Aschman DJ, Holmberg SD. Declining morbidity and mortality among patients with advanced human immunodeficiency virus infection. HIV Outpatient Study Investigators. N Engl J Med. 1998;338(13):853-60.

3. Mocroft A, Ledergerber B, Katlama C, Kirk O, Reiss P, d'Arminio Monforte A, Knysz B, Dietrich M, Phillips AN, Lundgren JD. Decline in the AIDS and death rates in the EuroSIDA study: an observational study. Lancet. 2003; 362(9377):22-9.

4. Bangsberg DR, Ragland K, Monk A, Deeks SG. A single tablet regimen is associated with higher adherence and viral suppression than multiple tablet regimens in HIV+ homeless and marginally housed people. AIDS. 2010; 24(18):2835-40.

5. Nachega JB, Parienti JJ, Uthman OA, Gross R, Dowdy DW, Sax PE, Gallant JE, Mugavero MJ, Mills EJ, Giordano TP. Lower pill burden and once-daily antiretroviral treatment regimens for HIV infection: A meta-analysis of randomized controlled trials. Clin Infect Dis. 2014;58(9):1297-307.

6. Lima VD, Hogg RS, Harrigan PR, Moore D, Yip B, Wood E, Montaner JS Continued improvement in survival among HIV-infected individuals with newer forms of highly active antiretroviral therapy. AIDS. 2007;21(6):685-92.

7. World Health Organization (WHO): HIV/AIDS in Europe - Moving from death sentence to chronic disease management. Accessed at: http://www.euro. who.int/en/what-we-publish/abstracts/hivaids-in-europe.-moving-fromdeath-sentence-to-chronic-disease-management on August 16, 2016: WHO Regional Office for Europe; 2006.

8. Samji H, Cescon A, Hogg RS, Modur SP, Althoff KN, Buchacz K, Burchell AN, Cohen M, Gebo KA, Gill MJ, et al. Closing the gap: increases in life expectancy among treated HIV-positive individuals in the United States and Canada. PLoS One. 2013;8(12):e81355.

9. Mills EJ, Bakanda C, Birungi J, Chan K, Ford N, Cooper CL, Nachega JB, Dybul M, Hogg RS. Life expectancy of persons receiving combination antiretroviral therapy in low-income countries: a cohort analysis from Uganda. Ann Intern Med. 2011;155(4):209-16.

10. Antiretroviral Therapy Cohort Collaboration. Life expectancy of individuals on combination antiretroviral therapy in high-income countries: a collaborative analysis of 14 cohort studies. Lancet. 2008;372(9635):293-9.

11. Mocroft A, Brettle R, Kirk O, Blaxhult A, Parkin JM, Antunes F, Francioli P, D'Arminio Monforte A, Fox Z, Lundgren JD, et al. Changes in the cause of death among HIV positive subjects across Europe: results from the EuroSIDA study. AIDS. 2002;16(12):1663-71.

12. Crum NF, Riffenburgh RH, Wegner S, Agan BK, Tasker SA, Spooner KM, Armstrong AW, Fraser S, Wallace MR, Triservice ACC. Comparisons of causes of death and mortality rates among HIV-infected persons: analysis of the pre-, early, and late HAART (highly active antiretroviral therapy) eras. J Acquir Immune Defic Syndr. 2006;41(2):194-200.

13. Krentz HB, Kliewer G, Gill MJ. Changing mortality rates and causes of death for HIV-infected individuals living in Southern Alberta, Canada from 1984 to 2003. HIV Med. 2005;6(2):99-106.

14. Antiretroviral Therapy Cohort Collaboration. Causes of death in HIV-1-infected patients treated with antiretroviral therapy, 1996-2006: collaborative analysis of 13 HIV cohort studies. Clin Infect Dis. 2010;50(10):1387-96.

15. Palella Jr FJ, Baker RK, Moorman AC, Chmiel JS, Wood KC, Brooks JT, Holmberg SD, Investigators HIVOS. Mortality in the highly active antiretroviral therapy era: changing causes of death and disease in the HIV outpatient study. J Acquir Immune Defic Syndr. 2006;43(1):27-34.

16. Leone S, Gregis G, Quinzan G, Velenti D, Cologni G, Soavi L, Ravasio V, Ripamonti D, Suter F, Maggiolo F. Causes of death and risk factors among HIV-infected persons in the HAART era: analysis of a large urban cohort. Infection. 2011;39(1):13-20.

17. Hogg RS, Heath KV, Strathdee SA, Montaner JS, O'Shaughnessy MV, Schechter MT. HIV/AIDS mortality in Canada: evidence of gender, regional and local area differentials. AIDS. 1996;10(8):889-94.

18. Lima VD, Lepik KJ, Zhang W, Muldoon KA, Hogg RS, Montaner JS. Regional and temporal changes in HIV-related mortality in British Columbia, 19872006. Can J Public Health. 2010;101(5):415-9.

19. Belvedere $L M$, Miller $C L$, Hogg RS. Shifting sands: changing regional and gender-specific patterns of HIV/AIDS mortality in Canada, 1987 to 2008. Can J Public Health. 2012;103(3):202-6.

20. Lima VD, Eyawo O, Ma H, Lourenco L, Chau W, Hogg RS, Montaner JS. The impact of scaling-up combination antiretroviral therapy on patterns of mortality among HIV-positive persons in British Columbia, Canada. J Int AIDS Soc. 2015;18:20261.

21. Cheung CC, Ding E, Sereda P, Yip B, Lourenco L, Barrios R, Montaner J, Hogg RS, Lima V, Moore DM. Reductions in all-cause and cause-specific mortality among HIV-infected individuals receiving antiretroviral therapy in British Columbia, Canada: 2001-2012. HIV Med. 2016;17(9):694-701.

22. BC Centre for Excellence in HIV/AIDS. Drug Treatment Program and Laboratory. BC Centre for Excellence in HIV/AIDS; 2014. http://www.cfenet. ubc.ca/drug-treatment-program and http://www.cfenet.ubc.ca/research/ laboratory-program

23. Population Data BC: About Population Data BC. Accessed at: http://www. popdata.bc.ca/aboutus on January 17, 2017: Population Data BC; 2017.

24. British Columbia Ministry of Health (2014). Medical Services Plan (MSP) Payment Information File. Population Data BC. Data Extract. MOH. 2014. http://www.popdata.bc.ca/data.

25. British Columbia Ministry of Health (2014). Consolidation File (MSP Registration \& Premium Billing). Population Data BC. Data Extract. MOH. 2014. http://www.popdata.bc.ca/data.

26. Canadian Institute for Health Information (2014). Discharge Abstract Database (Hospital Separations). Population Data BC. Data Extract. MOH. 2014. http://www.popdata.bc.ca/data.

27. BC Cancer Agency Registry Data (2014). Population Data BC. Data Extract. BC Cancer Agency; 2014. http://www.popdata.bc.ca/data.

28. British Columbia Ministry of Health (2012). Mental Health. Population Data BC. Data Extract. MOH. 2014. http://www.popdata.bc.ca/data.

29. British Columbia Ministry of Health. PharmaCare. Population Data BC. Data Extract. MOH. 2014. http://www.popdata.bc.ca/data.

30. British Columbia Ministry of Health (2014). PharmaNet. BC Ministry of Health Data Extract. Data Stewardship Committee. 2014. http.//www.popdata.bc.ca/data.

31. British Columbia Vital Statistics Agency (2014). Vital Statistics Deaths. Population Data BC. Data Extract. BC Vital Statistics Agency. 2014. http:// www.popdata.bc.ca/data.

32. Nosyk B, Colley G, Yip B, Chan K, Heath K, Lima VD, Gilbert M, Hogg RS, Harrigan PR, Montaner JS. Application and validation of case-finding algorithms for identifying individuals with human immunodeficiency virus from administrative data in British Columbia, Canada. PLoS One. 2013;8(1):e54416.

33. Chiang CL: Standard error of the age-adjusted death rate. In: Vital Statistics Special Reports Volume 47, edn. Edited by US Department of Health Education and Welfare; 1961: 271-285.

34. Breslow NE, Day NE. Statistical methods in cancer research. Volume $\|-T$ The design and analysis of cohort studies. IARC Sci Publ. 1987;82:1-406.

35. Statistics Canada: Table 051-0001 - Estimates of population, by age group and sex for July 1, Canada, provinces and territories, annual. CANSIM 
database. Accessed at: http://www5.statcan.gc.ca/cansim/a26?lang=eng\&id= 510001 on January 17, 2017: Statistics Canada; 2015.

36. Martinez E, Milinkovic A, Buira E, de Lazzari E, Leon A, Larrousse M, Lonca M, Laguno M, Blanco JL, Mallolas J, et al. Incidence and causes of death in HIVinfected persons receiving highly active antiretroviral therapy compared with estimates for the general population of similar age and from the same geographical area. HIV Med. 2007;8(4):251-8.

37. Lohse N, Hansen AB, Pedersen G, Kronborg G, Gerstoft J, Sorensen HT, Vaeth $M$, Obel N. Survival of persons with and without HIV infection in Denmark, 1995-2005. Ann Intern Med. 2007;146(2):87-95.

38. Croxford S, Kitching A, Desai S, Kall M, Edelstein M, Delpech V. Survival and causes of death among people diagnosed with HIV infection in England and Wales in the era of effective antiretroviral therapy. HIV Med. 2015;16 Suppl 2:47.

39. Lewden C, Salmon D, Morlat P, Bevilacqua S, Jougla E, Bonnet F, Heripret L, Costagliola D, May T, Chene G, et al. Causes of death among human immunodeficiency virus (HIV)-infected adults in the era of potent antiretroviral therapy: emerging role of hepatitis and cancers, persistent role of AIDS. Int J Epidemiol. 2005;34(1):121-30.

40. Smith CJ, Ryom L, Weber R, Morlat P, Pradier C, Reiss P, Kowalska JD, de Wit S, Law M, el Sadr W, et al. Trends in underlying causes of death in people with HIV from 1999 to 2011 (D:A:D): a multicohort collaboration. Lancet. 2014;384(9939):241-8.

41. Aldaz P, Moreno-lribas C, Eques N, Irisarri F, Floristan Y, Sola-Boneta J, MartinezArtola V, Sagredo M, Castilla J. Mortality by causes in HIV-infected adults: comparison with the general population. BMC Public Health. 2011;11:300.

42. Weber R, Ruppik M, Rickenbach M, Spoerri A, Furrer H, Battegay M, Cavassini M, Calmy A, Bernasconi E, Schmid P, et al. Decreasing mortality and changing patterns of causes of death in the Swiss HIV Cohort Study. HIV Med. 2013;14(4):195-207.

43. Arnold DM, Julian JA, Walker IR, Association of Hemophilia Clinic Directors of C. Mortality rates and causes of death among all HIV-positive individuals with hemophilia in Canada over 21 years of follow-up. Blood. 2006;108(2):460-4

44. Klein MB, Rollet-Kurhajec KC, Moodie EE, Yaphe S, Tyndall M, Walmsley S, Gill J, Martel-Laferriere V, Cooper C, Canadian Co-infection Cohort I. Mortality in HIV-hepatitis C co-infected patients in Canada compared to the general Canadian population (2003-2013). AIDS. 2014;28(13):1957-65.

45. van Sighem A, Danner S, Ghani AC, Gras L, Anderson RM, de Wolf F, Study ANOC. Mortality in patients with successful initial response to highly active antiretroviral therapy is still higher than in non-HIV-infected individuals. J Acquir Immune Defic Syndr. 2005;40(2):212-8.

46. BC Centre for Excellence in HIV/AIDS: Treatment as Prevention. Accessed at: http://www.cfenet.ubc.ca/tasp on January 16, 2017: BC Centre for Excellence in HIV/AIDS; 2017.

47. Montaner JS. Treatment as prevention —a double hat-trick. Lancet. 2011; 378(9787):208-9.

48. Montaner JS, Hogg RS, Wood E, Kerr T, Tyndall M, Levy AR, Harrigan PR. The case for expanding access to highly active antiretroviral therapy to curb the growth of the HIV epidemic. Lancet. 2006;368(9534):531-6.

49. Joy R, Druyts EF, Brandson EK, Lima VD, Rustad CA, Zhang W, Wood E, Montaner JS, Hogg RS. Impact of neighborhood-level socioeconomic status on HIV disease progression in a universal health care setting. J Acquir Immune Defic Syndr. 2008;47(4):500-5.

50. Collaboration of Observational HIV Epidemiological Research Europe in EuroCoord (COHERE), Lewden C, Bouteloup V, De Wit S, Sabin C, Mocroft A, Wasmuth JC, van Sighem A, Kirk O, Obel N, et al. All-cause mortality in treated HIV-infected adults with $C D 4 \geq 500 / \mathrm{mm} 3$ compared with the general population: evidence from a large European observational cohort collaboration. Int J Epidemiol. 2012;41(2):433-45.

\section{Submit your next manuscript to BioMed Central and we will help you at every step:}

- We accept pre-submission inquiries

- Our selector tool helps you to find the most relevant journal

- We provide round the clock customer support

- Convenient online submission

- Thorough peer review

- Inclusion in PubMed and all major indexing services

- Maximum visibility for your research

Submit your manuscript at www.biomedcentral.com/submit

) Biomed Central 